\title{
Article \\ Clinical Outcome of Hospitalized COVID-19 Patients with History of Atrial Fibrillation
}

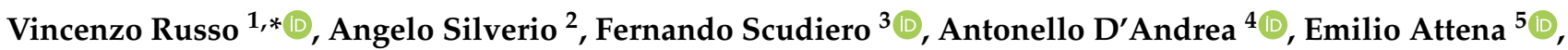 \\ Gisella Di Palma ${ }^{6}$, Guido Parodi ${ }^{7}$ (D), Valentina Caso ${ }^{1}$, Stefano Albani ${ }^{8}$ (D), Gennaro Galasso ${ }^{2}$, \\ Egidio Imbalzano ${ }^{9}$, Paolo Golino ${ }^{1}$ and Marco Di Maio ${ }^{2}$
}

check for updates

Citation: Russo, V.; Silverio, A.; Scudiero, F.; D'Andrea, A.; Attena, E.; Di Palma, G.; Parodi, G.; Caso, V.; Albani, S.; Galasso, G.; et al. Clinical Outcome of Hospitalized COVID-19 Patients with History of Atrial Fibrillation. Medicina 2022, 58, 399. https://doi.org/10.3390/ medicina58030399

Academic Editor: Stefano De Servi

Received: 20 January 2022

Accepted: 3 March 2022

Published: 7 March 2022

Publisher's Note: MDPI stays neutral with regard to jurisdictional claims in published maps and institutional affiliations.

Copyright: (C) 2022 by the authors. Licensee MDPI, Basel, Switzerland. This article is an open access article distributed under the terms and conditions of the Creative Commons Attribution (CC BY) license (https:// creativecommons.org/licenses/by/ $4.0 /)$.
1 Cardiology Unit, Department of Translational Medical Sciences, University of Campania “Luigi Vanvitelli"-Monaldi Hospital, 80131 Naples, Italy; valepica8@yahoo.it (V.C.); paolo.golino@unicampania.it (P.G.)

2 Department of Medicine, Surgery and Dentistry, University of Salerno, 84084 Baronissi, Italy; angelosilverio1988@gmail.com (A.S.); ggalasso@unisa.it (G.G.); marcodimaio88@gmail.com (M.D.M.)

3 Cardiology Unit, Health Authority Bergamo East, 24121 Bargamo, Italy; fernandoscudiero@gmail.com

4 Cardiology and Intensive Care Unit, Umberto I Hospital, 84014 Nocera Inferiore, Italy; antonellodandrea@libero.it

5 Cardiology Unit, Cotugno Hospital, 80131 Naples, Italy; emilioattena@hotmail.it

6 Medicine Unit, Santa Maria di Loreto Nuovo Hospital, 80142 Naples, Italy; gisella80@inwind.it

7 Clinical and Interventional Cardiology, Sassari University Hospital, 07100 Sassary, Italy; parodiguido@gmail.com

8 Cardiology Department, Aosta Valley Health Authority, 11100 Aosta, Italy; albani.aosta@gmail.com

9 Department of Clinical and Experimental Medicine, University of Messina, 98122 Messina, Italy; egidio.imbalzano@unime.it

* Correspondence: v.p.russo@libero.it

Abstract: Background and objectives: Pre-existing atrial fibrillation (AF) is a frequent comorbidity in hospitalized patients with COVID-19; however, little is still known about its prognostic role in infected patients. The aim of our study was to evaluate whether the pre-existing AF as comorbidity would contribute to increase the risk for severe forms of COVID-19, worse prognosis, or even higher mortality. Materials and Methods: We retrospectively evaluated all consecutive COVID-19 patients admitted to the emergency department of nine Italian Hospitals from 1 March to 30 April 2020.The prevalence and the type of pre-existing AF have been collected. The correlation between the history and type of AF and the development of severe ARDS and in-hospital mortality has been evaluated. Results: In total, 467 patients (66.88 \pm 14.55 years; $63 \%$ males) with COVID-19 were included in the present study. The history of AF was noticed in 122 cases $(26.1 \%)$, of which 12 (2.6\%) with paroxysmal, $57(12.2 \%)$ with persistent and $53(11.3 \%)$ with permanent AF. Among our study population, COVID-19 patients with AF history were older compared to those without AF history (71.25 \pm 12.39 vs. $65.34 \pm 14.95$ years; $p<0.001)$; however, they did not show a statistically significant difference in cardiovascular comorbidities or treatments. Pre-existing AF resulted in being independently associated with an increased risk of developing severe ARDS during the hospitalization; in contrast, it did not increase the risk of in-hospital mortality. Among patients with AF history, no significant differences were detected in severe ARDS and in-hospital mortality between patients with permanent and non-permanent AF history. Conclusions: Pre-existing AF is a frequent among COVID-19 patients admitted to hospital, accounting up to $25 \%$ of cases. It is independently associated with an increased risk of severe ARDS in hospitalized COVID-19 patients; in contrast, it did not affect the risk of death. The type of pre-existing AF (permanent or non-permanent) did not impact the clinical outcome.

Keywords: novel coronavirus; SARS-CoV-2; COVID-19; atrial fibrillation; mortality; outcome 


\section{Introduction}

Coronavirus disease 2019 (COVID-19) is the infectious disease caused by the severe acute respiratory syndrome coronavirus 2 (SARS-CoV-2), a highly pathogenic human coronavirus responsible for an epidemic of devasting proportion [1]. During the first pandemic wave, Italy was one of the countries with the highest number of confirmed cases [2,3]. The incidence of atrial fibrillation (AF) may complicate the clinical course of COVID-19 [4], and it seems to negatively impact on the prognosis of hospitalized patients [5-7]. The pre-existing AF could potentially impact on the clinical outcome of hospitalized patients with critical illness because it may increase the overall body inflammation and reduce the ability to compensate the hemodynamic alterations of acute illness. Actually, few data have been reported about the prognosis of hospitalized COVID-19 patients with AF history. The aim of our study was to evaluate whether the history of AF as comorbidity and the type pre-existing AF would contribute to increase the risk for severe forms of COVID-19, worse prognosis, or even higher mortality.

\section{Materials and Methods}

\subsection{Study Design and Population}

We performed an observational retrospective analysis of consecutive COVID-19 patients admitted to nine Italian Hospitals from 1 March to 30 April 2020. The clinical characteristics, pharmacological therapy and pre-existing-type AF (paroxysmal, persistent, or permanent) have been collected. We dichotomized the study population into two groups according to the pre-existence of AF as comorbidity (no-AF history vs. AF history group). Moreover, we additionally dichotomized patients with AF history into those with and without permanent AF (Non-permanent vs. permanent AF history groups). The diagnosis of AF history was made on the basis of at least 1 AF episode recorded at 12-lead electrocardiographic (ECG) or continuous ambulatory ECG monitoring. Patients with incomplete baseline ( $n$ : 67$)$ or follow-up data ( $n$ : 37$)$ were excluded.

\subsection{Clinical Outcomes}

The differences in terms of occurrence of severe ARDS in need of intensive care unit (ICU) and in-hospital mortality have been evaluated. ARDS was defined according to the Berlin definition [8]. The severe form of ARDS based on the degree of hypoxemia was diagnosed when the ration between arterial oxygen tension $\left(\mathrm{PaO}_{2}\right)$ and the fraction of inspired oxygen $\left(\mathrm{FIO}_{2}\right)$ was $\leq 100 \mathrm{~mm} \mathrm{Hg}$ with positive-end expiratory pressure $(\mathrm{PEEP}) \geq 5 \mathrm{~cm} \mathrm{H}_{2} \mathrm{O}$. The number of patients who experienced thromboembolic complications and pulmonary embolism was recorded. This study was conducted according to the Declaration of Helsinki and approved by the institutional ethics committees. The requirement for informed consent from individual patients was waived due to the observational retrospective design of the study.

\subsection{Statistical Analysis}

The Kolmogorov-Smirnov and the Shapiro-Wilk test were used to test the distribution of continuous data. Mean \pm standard deviation (SD) and median with interquartile range (IQR) were used to express the normally and non-normally distributed variables, respectively. Categorical variables were expressed as numbers and percentages. Student t-test and Mann-Whitney $U$ test were used to compare the continuous normally and nondistributed variables, respectively. Chi-squared test, or Fisher exact test, when appropriate, was used to compare the categorical variables. To assess the impact of AF history on outcomes in the overall population and of the permanent AF among patients with AF history, logistic regression models were performed, and the results were expressed with the risk ratios (RR) and their 95\% confidence intervals (CI). All pre-procedural covariates potentially related to the outcome were included in the propensity score weighting model Two different propensity score weighting models, including age, sex, smoking habit, chronic obstructive pulmonary disease (COPD), hypertension, diabetes, coronary artery disease 
(CAD), heart failure, obesity, dyslipidemia, stroke, and chronic kidney disease (CKD), were used to account for potential bias between the study groups (AF history vs. no AF history and permanent AF history vs. non-permanent AF history). After weighting, standardized mean differences were calculated to assess the balance for all covariates included in the propensity score models; values higher than 0.10 were considered significant for differences among groups. A $p$-value $<0.05$ was determined to be significant. Statistical tests were performed in $\mathrm{R}$ version 3.5.1 (R Foundation for Statistical Computing, Vienna, Austria).

\section{Results}

We included in the present study 467 consecutive COVID-19 patients (mean age $66.88 \pm 14.55$ years; $63 \%$ males) followed for a median time of 28 days (IQR: $12-45$ ).

The inclusion graph of the study population was shown in Figure 1.

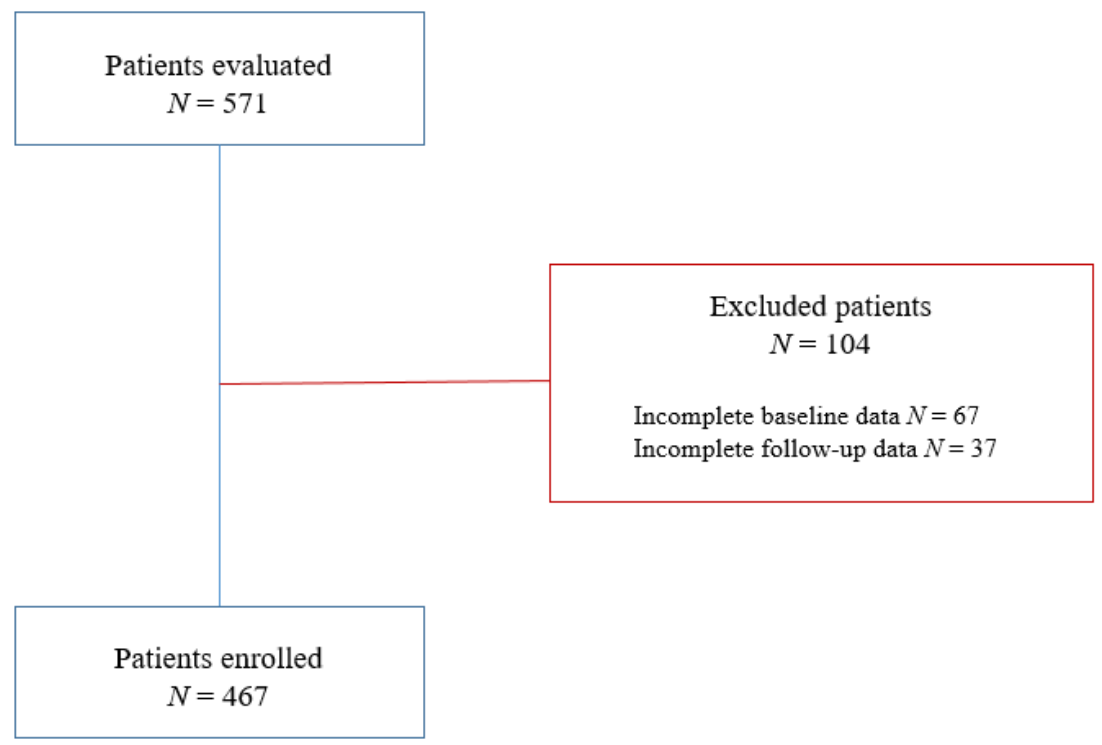

Figure 1. Inclusion graph of the study population.

The history of AF was noticed in 122 cases (26.1\%), of which $12(2.6 \%)$ had paroxysmal $\mathrm{AF}, 57(12.2 \%)$ had persistent AF, and 53 (11.3\%) had permanent AF. COVID-19 patients with pre-existing AF (AF history group) were older compared to those without pre-existing AF (No-AF history Groups) (71.25 \pm 12.39 vs. $65.34 \pm 14.95$ years; $p<0.001)$ and were more likely to be taking anticoagulant therapy $(40.9 \%$ vs. $11.0 \% ; p<0.001)$; however, they did not show statistical differences in cardiovascular comorbidities or treatments, except for the history of stroke $(13.9 \%$ vs. $7.2 \%$; $p=0.042)$. The clinical features of the study population are shown in Table 1 . All enrolled patients were treated with the same therapeutic protocol based a triple combination including Lopinavir/Ritonavir (250/50 mg twice daily), Hydroxychloroquine (200 mg twice daily), and Azithromycin (500 mg once daily). All hospitalized patients showed fever and dyspnea.

Table 1. Characteristics of the overall study population and differences between the two groups according to the presence or not of pre-existing AF.

\begin{tabular}{lcccc}
\hline & Overall & $\begin{array}{c}\text { No AF History } \\
\text { Group }\end{array}$ & $\begin{array}{c}\text { AF History } \\
\text { Group }\end{array}$ & $p$ \\
\hline$n$ & 467 & 345 & 122 & \\
\hline Male, $n(\%)$ & $294(63.0)$ & $225(65.2)$ & $69(56.6)$ & 0.111 \\
\hline Age, mean (SD) & $66.88(14.55)$ & $65.34(14.95)$ & $71.25(12.39)$ & $<0.001$ \\
\hline
\end{tabular}


Table 1. Cont.

\begin{tabular}{|c|c|c|c|c|}
\hline & Overall & $\begin{array}{l}\text { No AF History } \\
\text { Group }\end{array}$ & $\begin{array}{l}\text { AF History } \\
\text { Group }\end{array}$ & $p$ \\
\hline Smoker, $n(\%)$ & $79(16.9)$ & $62(18.0)$ & $17(13.9)$ & 0.378 \\
\hline Hypertension, $n(\%)$ & $289(61.9)$ & $207(60.0)$ & $82(67.2)$ & 0.193 \\
\hline Diabetes, $n(\%)$ & $123(26.3)$ & $86(24.9)$ & $37(30.3)$ & 0.296 \\
\hline Dyslipidemia, $n(\%)$ & $119(25.5)$ & $92(26.7)$ & $27(22.1)$ & 0.386 \\
\hline Obesity, $n(\%)$ & $35(13.3)$ & $28(13.7)$ & $7(12.1)$ & 0.924 \\
\hline Heart failure, $n(\%)$ & $35(7.5)$ & $22(6.4)$ & $13(10.7)$ & 0.179 \\
\hline History of Stroke, $n(\%)$ & $42(9.0)$ & $25(7.2)$ & $17(13.9)$ & 0.042 \\
\hline Chronic kidney disease, $n(\%)$ & $62(13.3)$ & $41(11.9)$ & $21(17.2)$ & 0.182 \\
\hline Coronary artery disease, $n(\%)$ & $71(15.2)$ & $58(16.8)$ & $13(10.7)$ & 0.139 \\
\hline $\begin{array}{l}\text { Chronic Obstructive Pulmonary } \\
\text { Disease, } n(\%)\end{array}$ & $90(19.3)$ & $67(19.4)$ & $23(18.9)$ & 0.997 \\
\hline Antiplatelet therapy, $n(\%)$ & $141(30.2)$ & $100(29.0)$ & $41(33.6)$ & 0.400 \\
\hline Double antiplatelet therapy (\%) & $19(4.1)$ & $12(3.5)$ & $7(5.7)$ & 0.413 \\
\hline Oral anticoagulant therapy, $n(\%)$ & $88(18.8)$ & $38(11.0)$ & $50(40.9)$ & $<0.001$ \\
\hline $\begin{array}{l}\text { Direct oral anticoagulant therapy, } \\
n(\%)\end{array}$ & $50(10.7)$ & $15(4.4)$ & $35(28.7)$ & $<0.001$ \\
\hline $\begin{array}{l}\text { Vitamin K antagonist therapy, } \\
n(\%)\end{array}$ & $32(6.9)$ & $18(5.2)$ & $14(11.5)$ & 0.032 \\
\hline $\begin{array}{l}\text { Low molecular weight heparin, } \\
n(\%)\end{array}$ & $135(28.9)$ & $63(18.2)$ & $65(53.3)$ & $<0.001$ \\
\hline Severe ARDS at admission, $n(\%)$ & $124(26.5 \%)$ & $86(24.9 \%)$ & $38(31 \%)$ & 0.189 \\
\hline AF at admission, $n(\%)$ & $62(13.3)$ & $1(0.3)$ & $61(50.0)$ & $<0.001$ \\
\hline Permanent AF, $n(\%)$ & $53(11.3)$ & $0(0.0)$ & $53(43.4)$ & - \\
\hline Non-permanent AF, $n(\%)$ & $69(14.8)$ & $0(0.0)$ & $69(56.6)$ & - \\
\hline Persistent AF, $n(\%)$ & $57(12.2)$ & $0(0.0)$ & $57(46.7)$ & - \\
\hline Paroxysmal AF, $n(\%)$ & $12(2.6)$ & $0(0.0)$ & $12(9.8)$ & - \\
\hline
\end{tabular}

Among COVID-19 patients with AF history, those with permanent AF history were more likely older compared to those with non-permanent AF history (68.58 \pm 11.17 vs. $74.74 \pm 13.13$ years; $p=0.006)$; no other significant differences were detected among the two groups (Table 2). The distributions of the propensity score values before and after weighting in pre-existing vs. non-preexisting AF and permanent vs. non-permanent AF history groups are plotted in Figure 2. A total of 7 out of 69 patients $(10.1 \%)$ with non-permanent AF history and in sinus rhythm at admission switched to AF during hospitalization.

Table 2. Characteristics and differences between the two groups according to history of nonpermanent or permanent AF.

\begin{tabular}{lccc}
\hline & $\begin{array}{c}\text { Non-Permanent } \\
\text { AF History } \\
\text { Group }\end{array}$ & $\begin{array}{c}\text { Permanent AF } \\
\text { History } \\
\text { Group }\end{array}$ & $p$ \\
\hline$n$ & 69 & 53 & 0.999 \\
\hline Male, $n(\%)$ & $39(56.5)$ & $30(56.6)$ & 0.006 \\
\hline Age, mean (SD) & $68.58(11.17)$ & $74.74(13.13)$ & \\
\hline
\end{tabular}


Table 2. Cont.

\begin{tabular}{lccc}
\hline & $\begin{array}{c}\text { Non-Permanent } \\
\text { AF History } \\
\text { Group }\end{array}$ & $\begin{array}{c}\text { Permanent AF } \\
\text { History } \\
\text { Group }\end{array}$ & $p$ \\
\hline Smoker, $n(\%)$ & $8(11.6)$ & $9(17.0)$ & 0.557 \\
\hline Hypertension, $n(\%)$ & $45(65.2)$ & $37(69.8)$ & 0.733 \\
\hline Diabetes, $n(\%)$ & $23(33.3)$ & $14(26.4)$ & 0.532 \\
\hline Dyslipidemia, $n(\%)$ & $14(20.3)$ & $13(24.5)$ & 0.735 \\
\hline Obesity, $n(\%)$ & $3(9.4)$ & $4(15.4)$ & 0.769 \\
\hline Heart failure, $n(\%)$ & $5(7.2)$ & $8(15.1)$ & 0.273 \\
\hline History of Stroke, $n(\%)$ & $9(13.0)$ & $8(15.1)$ & 0.952 \\
\hline Chronic kidney disease, $n(\%)$ & $12(17.4)$ & $9(17.0)$ & 0.999 \\
\hline Coronary artery disease, $n(\%)$ & $6(8.7)$ & $7(13.2)$ & 0.614 \\
\hline Chronic Obstructive Pulmonary Disease, & $10(14.5)$ & $13(24.5)$ & 0.241 \\
$n(\%)$ & $24(34.8)$ & $17(32.1)$ & 0.904 \\
\hline Antiplatelet therapy, $n(\%)$ & $6(8.7)$ & $1(1.9)$ & 0.226 \\
\hline Double antiplatelet therapy (\%) & $28(40.6)$ & $21(39.6)$ & 0.999 \\
\hline Oral Anticoagulant therapy, $n(\%)$ & $19(27.5)$ & $16(30.2)$ & 0.905 \\
\hline Direct oral anticoagulant therapy, $n(\%)$ & $9(13.0)$ & $5(9.4)$ & 0.739 \\
\hline Vitamin K antagonist therapy, $n(\%)$ & $33(47.8)$ & $17(32.1)$ & 0.999 \\
\hline Low molecular weight heparin, $n(\%)$ & $21(30.4)$ & & 0.17 \\
\hline Severe ARDS at admission, $n(\%)$ & & $(\% 0.3)$ & \\
\hline & & & \\
\hline
\end{tabular}

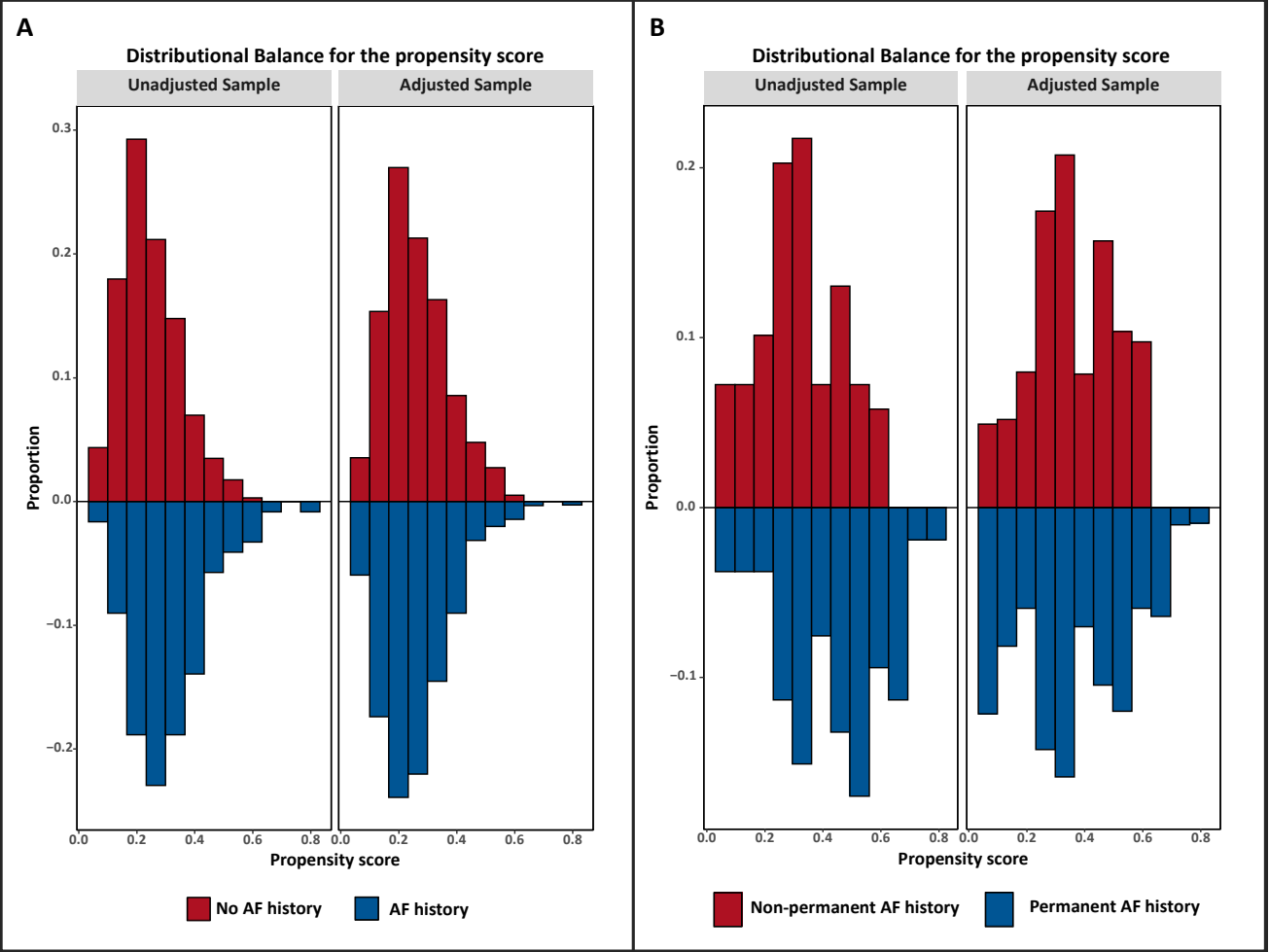

Figure 2. Distributional balance of the propensity score values before and after weighting between no AF history and AF history groups (A) and permanent vs. non-permanent AF history groups (B). 
Among overall study population, 124 patients (26.5\%) presented with severe ARDS at admission to the emergency department, 169 patients $(36.2 \%)$ developed severe ARDS during hospitalization and 107 died (22.9\%).

There was no statistically significant difference in severe ARDS at admission (31\% vs. $24.9 \%, p$ : 0.189$)$, severe ARDS during hospitalization (13.9\% vs. $8.1 \% ; p=0.07)$, and overall mortality $(24.6 \%$ vs. $22.3 \%$, $p$ : 0.604$)$ between the AF history and No-AF history groups. At weighted analysis, the history of AF was significantly associated with increased risk of any ARDS (RR: 1.38; $p=0.021$ ); a trend of association with ARDS during the hospitalization (RR: $1.78 ; p=0.074)$ was shown; no remarkable associations with mortality among COVID-19 patients (RR: $0.94 ; p=0.754$ ) were found (Figure 3 ).

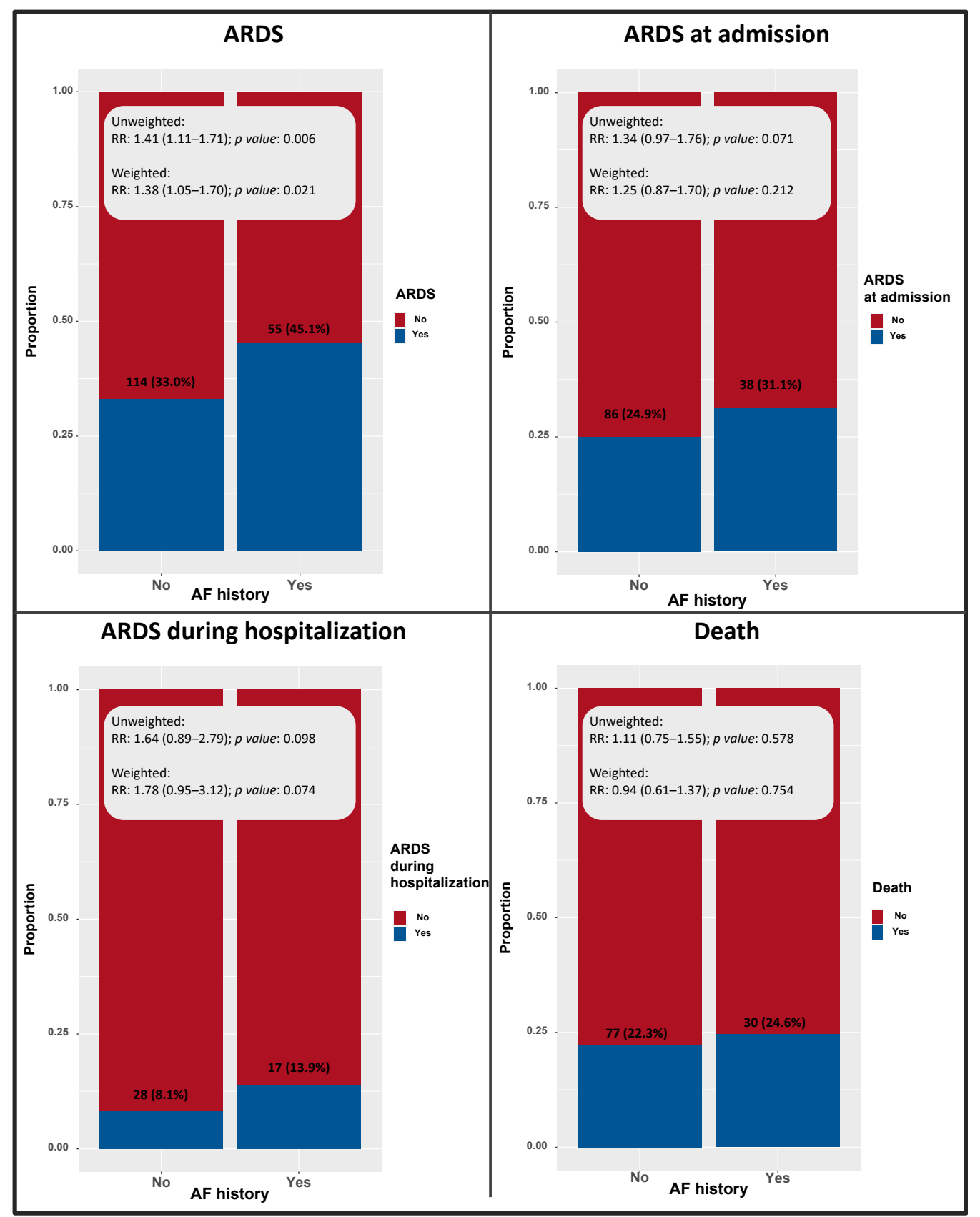

Figure 3. Prevalence and risk ratio of the outcome of interest among patients with and without AF history. 
Moreover, no significant differences in the incidence of outcome events were detected between patients with permanent and non-permanent AF history (Figure 4).

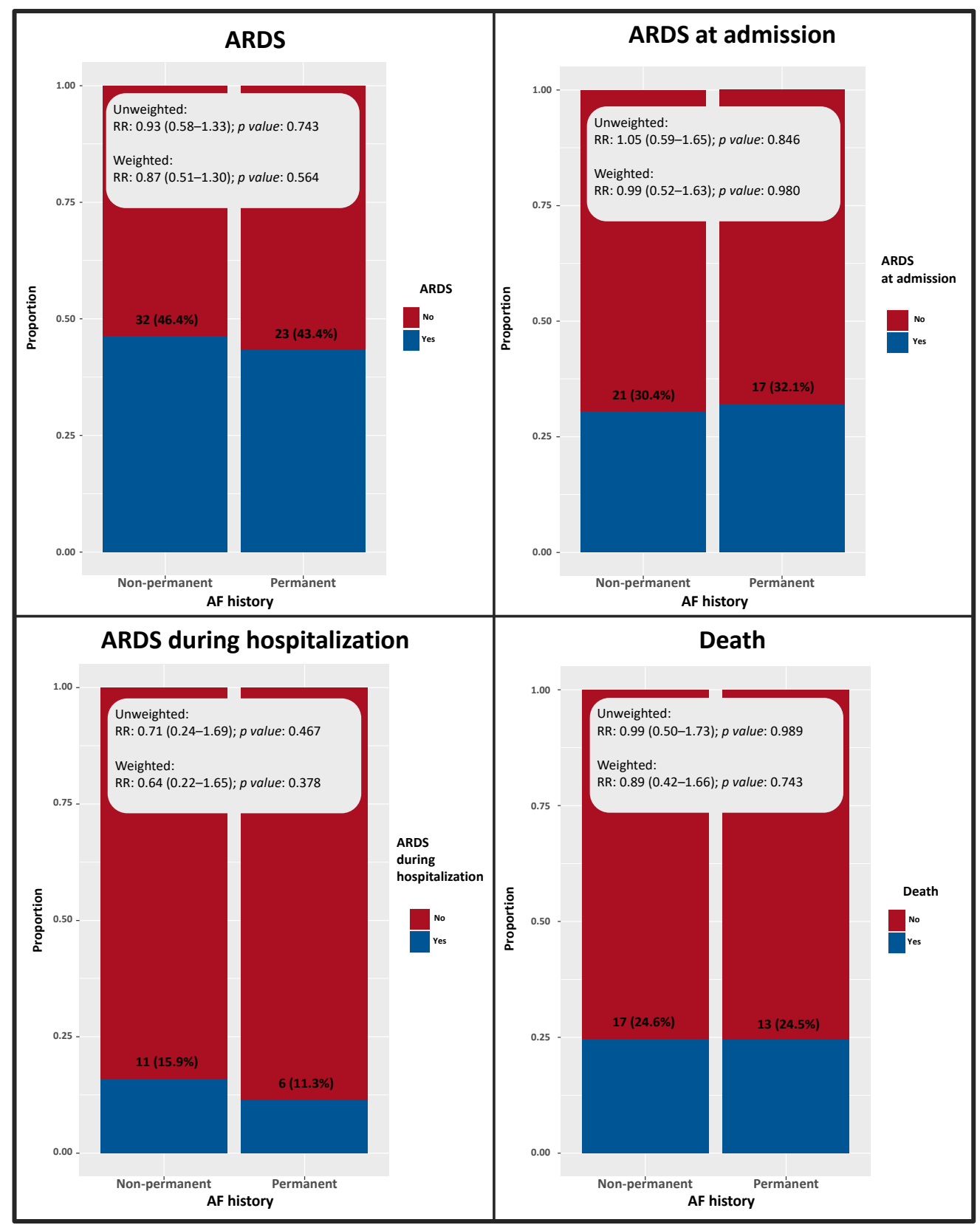

Figure 4. Prevalence and risk ratio of the outcome of interest among patients with non-permanent and permanent AF history.

Among the overall study population, 88 patients were on oral anticoagulation at baseline. There was no statistically significant difference between patients with and without oral anticoagulant therapy in terms of ARDS at admission (26\% vs. $28 \%, p$ : 0.834$)$ and ARDS during the hospitalization ( $9 \%$ vs. $10 \% ; p=0.915)$. Among the No-AF history group, 51 patients (14.8\%) experienced new-onset AF during hospitalization. There was no significant difference in terms of ARDS (at admission or during hospitalization) occurrence (40.7\% vs. $31.5 \%$, p: 0.173$)$ and overall mortality (23.7\% vs. $22.0 \%$, p: 0.775$)$ between No-AF history patients who experienced or not new-onset AF. Finally, we noticed 12 thrombotic complications $(2.56 \%$ ) during the hospitalization ( 4 stroke and 8 acute myocardial infarction) and 18 pulmonary embolisms (3.85\%). 


\section{Discussion}

The present study showed that 25\% of hospitalized COVID-19 patients had personal history of atrial fibrillation, confirming that AF is a frequent comorbidity in this clinical setting. Moreover, pre-existing AF was independently associated with an increased risk of ARDS; in contrast, it did not affect the risk of in-hospital mortality. The type of pre-existing AF (permanent or non-permanent) did not impact the clinical outcome of hospitalized COVID-19 patients.

Despite the well-known association between cardiovascular diseases (CVD), including atrial fibrillation, and COVID-19 [9-12], little is known about the prognostic impact of pre-existing AF in hospitalized COVID-19 patients [13-17], and few data are available about the association between different forms of AF (permanent vs. non-permanent) and clinical outcomes [18].

Inciardi et al., among 99 patients hospitalized for COVID-19 in Northern Italy, reported an overall prevalence of $19 \%$, which increases to $36 \%$ in those with cardiovascular diseases and $42 \%$ among patients who died during the hospitalization [13]; moreover, the history of AF was reported in 75\% of geriatric patients with COVID-19 [14].

The data provided by the COVID-19 Task Force of the Italian National Institute of Health reported that AF was present in $24.5 \%$ of 355 non-surviving COVID-19 patients (mean age 79.5 years, $70 \%$ men) before the SARS-CoV-2 infection [15]. Moreover, the report of the New York State Department of Health showed that AF is the seventh among COVID-19 comorbidities [19].

Whether atrial fibrillation should be considered a cardiovascular risk factor associated with a worse prognosis in COVID-19 patients is still debated [20]; a low AF prevalence, about 3\%, has been reported among COVID-19 patients not requiring hospitalization [21]. A recent metanalysis by Zuin et al. [18] including 15,562 COVID-19 patients across 12 different observational studies showed that pre-existing AF was associated with an increased risk of short-term mortality; however, the effects of the type of AF (permanent or non-permanent) were not investigated.

According to our results, the AF history seems to impact the clinical outcome of COVID-19 patients, increasing the risk of ARDS and suggesting that AF should be considered, among cardiovascular comorbidities, a red flag of worsening respiratory disease. The link between pre-existing AF and ARDS incidence in the clinical contest of COVID-19 might be related to the increased ACE2 expression in AF patients [22], which may promote the cell binding of SARS-CoV-2 and the inflammatory host response [23]. Based on this hypothesis, AF may be the arrhythmic marker of underlying inflammatory substrate favoring, and then amplified by, COVID-19 and leading to worse respiratory outcomes.

According to our results, the history of AF did not influence the risk of in-hospital mortality. These results diverge from the study by Gamst et al., who demonstrated a significant correlation between AF and mortality in a population-based cohort study including patients admitted in the intensive care unit [24]. Advanced age, male gender, ischemic heart disease, chronic kidney disease; some laboratory markers of oxygenation deficit, renal, and microvascular dysfunction; and coagulation activation have been significantly associated with the risk of in-hospital mortality $[25,26]$. Of note, the prevalence of these conditions was substantially lower in our population compared to what was reported by Gamst et al. [24] in the intensive care setting and may justify the discrepancy between the results of these studies. Recently, two metanalysis [27,28] suggested that COVID-19 patients with new-onset AF showed a significantly increased risk of all-cause mortality compared to those without AF; however, no data about the prognostic value of pre-existing AF have been provided. Our results suggest that the clinical outcome of hospitalized COVID-19 patients was not influenced by the type of pre-existing AF (permanent or non-permanent).

As previously showed $[29,30]$, the preadmission antithrombotic therapy did not seem to show a protective effect in severe forms of COVID-19 with ARDS at presentation and rapidly evolving toward death. Among our study population, the incidence of thromboembolic events and pulmonary embolism was similar to those previously showed $[4,17,31]$. 
In the light of these results, we recommend following the international guidelines for vulnerable people living with chronic disease also for AF patients. Thereafter, careful clinical monitoring would be advisable in hospitalized COVID-19 patients with AF to early detect patients with a higher risk to develop ARDS during hospitalization.

\section{Study Limitations}

The present study has several limitations related to the observational retrospective design and the heterogeneity of COVID-19 clinical presentation. Although the study population was relatively small, we reported a high rate of adverse events to substantiate our analysis. To avoid the risk of overfitting due to an excess of variables examined compared to the number of events, we employed the propensity score weighting technique. Due to the absence of computed tomography imaging data, the COVID-19 severity was assessed on the basis of the presence of severe ARDS at admission. Further studies including a larger number of patients and different virus variants are needed.

\section{Conclusions}

Pre-existing atrial fibrillation is a frequent comorbidity in hospitalized COVID-19 patients, and it was independently associated to the ARDS but not to in-hospital mortality. The type of pre-existing AF (permanent vs. non-permanent) did not impact the clinical outcomes. Pre-existing AF should be considered a marker of increased vulnerability to worse respiratory disease during COVID-19. Careful monitoring and treatment are needed for this subgroup of patients.

Author Contributions: Conceptualization, V.R. and A.S.; methodology, M.D.M.; software, F.S.; validation, A.D., G.D.P. and E.A.; formal analysis, M.D.M.; investigation, E.I. and G.G.; resources, V.R.; data curation, A.S. and M.D.M.; writing—original draft preparation, V.R.; writing-review and editing, G.G.; visualization, P.G.; supervision, G.P.; project administration, V.C.; funding acquisition, S.A. All authors have read and agreed to the published version of the manuscript.

Funding: This research received no external funding.

Institutional Review Board Statement: The study was conducted according to the guidelines of the Declaration of Helsinki, and approved by Local Ethical Committee (ID-168/02032021).

Informed Consent Statement: Informed consent was obtained from all subjects involved in the study.

Data Availability Statement: The data presented in this study are available on request from the corresponding author.

Conflicts of Interest: The authors declare no conflict of interest.

\section{References}

1. Hui, D.S.; IAzhar, E.; Madani, T.A.; Ntoumi, F.; Kock, R.; Dar, O.; Ippolito, G.; Mchugh, T.D.; Memish, Z.A.; Drosten, C.; et al. The continuing 2019-nCoV epidemic threat of novel coronaviruses to global health-The latest 2019 novel coronavirus outbreak in Wuhan, China. Int. J. Infect. Dis. 2020, 91, 264-266. [CrossRef] [PubMed]

2. Silverio, A.; Di Maio, M.; Ciccarelli, M.; Carrizzo, A.; Vecchione, C.; Galasso, G. Timing of national lockdown and mortality in COVID-19: The Italian experience. Int. J. Infect. Dis. 2020, 100, 193-195. [CrossRef] [PubMed]

3. World Health Organization. Coronavirus Disease (COVID-19). Situation Report. Available online: https://www.who.int/docs/ default-source / coronaviruse/ situation-reports /20201020-weekly-epi-update-10.pdf?sfvrsn=58786643_26\&download=true (accessed on 19 December 2020).

4. Russo, V.; Rago, A.; Carbone, A.; Bottino, R.; Ammendola, E.; Della Cioppa, N.; Galante, D.; Golino, P.; Nigro, G. Atrial Fibrillation in COVID-19: From Epidemiological Association to Pharmacological Implications. J. Cardiovasc. Pharmacol. 2020, 76, 138-145. [CrossRef] [PubMed]

5. Bhatla, A.; Mayer, M.M.; Adusumalli, S.; Hyman, M.C.; Oh, E.; Tierney, A.; Moss, J.; Chahal, A.A.; Anesi, G.; Denduluri, S.; et al. COVID-19 and cardiac arrhythmias. Heart Rhythm 2020, 17, 1439-1444. [CrossRef] [PubMed]

6. Colon, C.M.; Barrios, J.G.; Chiles, J.W.; McElwee, S.K.; Russell, D.W.; Maddox, W.R.; Kay, G.N. Atrial Arrhythmias in COVID-19 Patients. JACC Clin. Electrophysiol. 2020, 6, 1189-1190. [CrossRef] [PubMed] 
7. Russo, V.; Di Maio, M.; Mottola, F.F.; Pagnano, G.; Attena, E.; Verde, N.; Di Micco, P.; Silverio, A.; Scudiero, F.; Nunziata, L.; et al. Clinical characteristics and prognosis of hospitalized COVID-19 patients with incident sustained tachyarrhythmias: A multicenter observational study. Eur. J. Clin. Investig. 2020, 50, e13387. [CrossRef] [PubMed]

8. Ranieri, V.M.; Rubenfeld, G.D.; Thompson, B.T.; Ferguson, N.D.; Caldwell, E.; Fan, E.; Camporota, L.; Slutsky, A.S. Acute respiratory distress syndrome: The Berlin Definition. JAMA 2012, 307, 2526-2533. [CrossRef] [PubMed]

9. Richardson, S.; Hirsch, J.S.; Narasimhan, M.; Crawford, J.M.; McGinn, T.; Davidson, K.W.; Barnaby, D.P.; Becker, L.B.; Chelico, J.D.; Cohen, S.L.; et al. Presenting Characteristics, Comorbidities, and Outcomes among 5700 Patients Hospitalized with COVID-19 in the New York City Area. JAMA 2020, 323, 2052-2059. [CrossRef] [PubMed]

10. Russo, V.; Bottino, R.; Carbone, A.; Rago, A.; Papa, A.A.; Golino, P.; Nigro, G. COVID-19 and Heart: From Clinical Features to Pharmacological Implications. J. Clin. Med. 2020, 9, 1944. [CrossRef] [PubMed]

11. D'Andrea, A.; Russo, V.; Manzo, G.; Giordano, V.; Di Maio, M.; Crescibene, F.; D'Alto, M.; Bossone, E. Association of atrial fibrillation and left atrial volume index with mortality in patients with COVID-19 pneumonia. Eur. J. Prev. Cardiol. 2020, 9, zwaa138. [CrossRef]

12. Russo, V.; Silverio, A.; Scudiero, F.; Attena, E.; D'Andrea, A.; Nunziata, L.; Parodi, G.; Celentani, D.; Varbella, F.; Albani, S.; et al. Preadmission Statin Therapy and Clinical Outcome in Hospitalized Patients with COVID-19: An Italian Multicenter Observational Study. J. Cardiovasc. Pharmacol. 2021, 78, e94-e100. [CrossRef]

13. Inciardi, R.M.; Adamo, M.; Lupi, L.; Cani, D.S.; Di Pasquale, M.; Tomasoni, D.; Italia, L.; Zaccone, G.; Tedino, C.; Fabbricatore, D.; et al. Characteristics and outcomes of patients hospitalized for COVID-19 and cardiac disease in Northern Italy. Eur. Heart J. 2020, 41, 1821-1829. [CrossRef] [PubMed]

14. Fumagalli, S.; Salani, B.; Gabbani, L.; Mossello, E.; Ungar, A. Covid-19 cases in a no-Covid-19 geriatric acute care setting. A sporadic occurrence? Eur. J. Intern. Med. 2020, 77, 141-142. [CrossRef] [PubMed]

15. Onder, G.; Rezza, G.; Brusaferro, S. Case-Fatality Rate and Characteristics of Patients Dying in Relation to COVID-19 in Italy. JAMA 2020, 323, 1775-1776. [CrossRef]

16. Silverio, A.; Di Maio, M.; Citro, R.; Esposito, L.; Iuliano, G.; Bellino, M.; Baldi, C.; De Luca, G.; Ciccarelli, M.; Vecchione, C.; et al. Cardiovascular risk factors and mortality in hospitalized patients with COVID-19: Systematic review and meta-analysis of 45 studies and 18,300 patients. BMC Cardiovasc. Disord. 2021, 21, 23. [CrossRef] [PubMed]

17. Scudiero, F.; Silverio, A.; Di Maio, M.; Russo, V.; Citro, R.; Personeni, D.; Cafro, A.; D'Andrea, A.; Attena, E.; Pezzullo, S.; et al. Pulmonary embolism in COVID-19 patients: Prevalence, predictors and clinical outcome. Thromb. Res. 2021, 198, 34-39. [CrossRef] [PubMed]

18. Zuin, M.; Rigatelli, G.; Bilato, C.; Zanon, F.; Zuliani, G.; Roncon, L. Pre-existing atrial fibrillation is associated with increased mortality in COVID-19 Patients. J. Interv. Card. Electrophysiol. 2021, 62, 231-238. [CrossRef] [PubMed]

19. New York State Department of Health. Available online: https://covid19tracker.health.ny.gov/views/NYS-COVID19-Tracker/ NYSDOHCOVID-19Tracker-Fatalities?\%3Aembed=yes\&\%3Atoolbar=no\&\%3Atabs=n (accessed on 19 December 2020).

20. Sanchis-Gomar, F.; Perez-Quilis, C.; Lavie, C.J. Should atrial fibrillation be considered a cardiovascular risk factor for a worse prognosis in COVID-19 patients? Eur. Heart J. 2020, 41, 3092-3093. [CrossRef]

21. Russo, V.; Piccinocchi, G.; Mandaliti, V.; Annunziata, S.; Cimmino, G.; Attena, E.; Moio, N.; Di Micco, P.; Severino, S.; Trotta, R.; et al. Cardiovascular Comorbidities and Pharmacological Treatments of COVID-19 Patients Not Requiring Hospitalization. Int. J. Environ. Res. Public Health 2020, 18, 102. [CrossRef] [PubMed]

22. Walters, T.E.; Kalman, J.M.; Patel, S.K.; Mearns, M.; Velkoska, E.; Burrell, L.M. Angiotensin converting enzyme 2 activity and human atrial fibrillation: Increased plasma angiotensin converting enzyme 2 activity is associated with atrial fibrillation and more advanced left atrial structural remodelling. Europace 2017, 19, 1280-1287. [CrossRef] [PubMed]

23. Gaddam, R.R.; Chambers, S.; Bhatia, M. ACE and ACE2 in inflammation: A tale of two enzymes. Inflamm. Allergy Drug Targets 2014, 13, 224-234. [CrossRef] [PubMed]

24. Gamst, J.; Christiansen, C.F.; Rasmussen, B.S.; Rasmussen, L.H.; Thomsen, R.W. Pre-existing atrial fibrillation and risk of arterial thromboembolism and death in intensive care unit patients: A population-based cohort study. Crit. Care 2015, 19, 299. [CrossRef] [PubMed]

25. Lu, L.; Zhong, W.; Bian, Z.; Li, Z.; Zhang, K.; Liang, B.; Zhong, Y.; Hu, M.; Lin, L.; Liu, J.; et al. A comparison of mortality-related risk factors of COVID-19, SARS, and MERS: A systematic review and meta-analysis. J. Infect. 2020, 81, e18-e25. [CrossRef] [PubMed]

26. Wendel Garcia, P.D.; Fumeaux, T.; Guerci, P.; Heuberger, D.M.; Montomoli, J.; Roche-Campo, F.; Schuepbach, R.A.; Hilty, M.P. RISC-19-ICU Investigators: Prognostic factors associated with mortality risk and disease progression in 639 critically ill patients with COVID-19 in Europe: Initial report of the international RISC-19-ICU prospective observational cohort. EClinicalMedicine 2020, 25, 100449. [CrossRef] [PubMed]

27. Li, Z.; Shao, W.; Zhang, J.; Ma, J.; Huang, S.; Yu, P.; Zhu, W.; Liu, X. Prevalence of Atrial Fibrillation and Associated Mortality among Hospitalized Patients with COVID-19: A Systematic Review and Meta-Analysis. Front. Cardiovasc. Med. 2021, 8, 720129. [CrossRef] [PubMed]

28. Romiti, G.F.; Corica, B.; Lip, G.Y.H.; Proietti, M. Prevalence and Impact of Atrial Fibrillation in Hospitalized Patients with COVID-19: A Systematic Review and Meta-Analysis. J. Clin. Med. 2021, 10, 2490. [CrossRef] 
29. Russo, V.; Di Maio, M.; Attena, E.; Silverio, A.; Scudiero, F.; Celentani, D.; Lodigiani, C.; Di Micco, P. Clinical impact of preadmission antithrombotic therapy in hospitalized patients with COVID-19: A multicenter observational study. Pharmacol. Res. 2020, 159, 104965. [CrossRef]

30. Russo, V.; Bottino, R.; D’Andrea, A.; Silverio, A.; Di Maio, M.; Golino, P.; Nigro, G.; Valsecchi, O.; Attena, E.; Canonico, M.E.; et al. Chronic Oral Anticoagulation and Clinical Outcome in Hospitalized COVID-19 Patients. Cardiovasc. Drugs Ther. 2021, 14, 1-8. [CrossRef] [PubMed]

31. Langella, V.; Bottino, R.; Asti, A.; Maresca, G.; Di Palma, G.; Pomponi, D.; Sassone, C.; Imbalzano, E.; Russo, V. Edoxaban for the treatment of pulmonary embolism in hospitalized COVID-19 patients. Expert. Rev. Clin. Pharmacol. 2021, 14, 1289-1294. [CrossRef] 